\title{
Prospect of Ion Channel Inhibitors and Cholesterol Lowering Drugs to Combat COVID-19
}

\author{
Devendra Nath Tewari, Alok Kumar Chakrabarti* and Shanta Dutta \\ ICMR-National Institute of Cholera and Enteric Diseases, Beliaghata, Kolkata, India
}

*Corresponding author: Alok Kumar Chakrabarti, ICMR-National Institute of Cholera and Enteric Diseases, Beliaghata, Kolkata, 700010, India, E-mail: chakrabarti.alok@icmr.gov.in

Received: 05 Feb, 2021 | Accepted: 29 Mar, 2021 | Published: 05 Apr, 2021

Citation: Tewari DN, Chakrabarti AK, Dutta S (2021) Prospect of Ion Channel Inhibitors and Cholesterol Lowering Drugs to Combat COVID-19. J Emerg Dis Virol 6(2): dx.doi.org/10.16966/2473-1846.162

Copyright: (c) 2021 Tewari DN, et al. This is an open-access article distributed under the terms of the Creative Commons Attribution License, which permits unrestricted use, distribution, and reproduction in any medium, provided the original author and source are credited.

\begin{abstract}
Emergence of SARS-CoV-2 and associated COVID-19 pandemic is a major global healthcare problem because there is no specific drug to combat the disease. Number of infection is piling up day by day in exponential rate creating new record every week. Entire world is looking for urgent remedy but till now there is no specific treatment available for COVID-19 patients. In this critical situation, although vaccination is in its way, drug repurposing is very important which may be useful to overcome the unprecedented situation of COVID-19 pandemic. Cholesterol lowering drugs like statin therapy may be an additional support to combat the disease. Hexamethylene amiloride which has shown its effect in blocking E protein ion channels of coronaviruses leading to inhibition of viral replication may be considered for investigative trial.
\end{abstract}

Abbreviations: ARDS: Acute Respiratory Distress Syndrome; HMA: Hexamethylene Amiloride; TNF- $\alpha$ : Tumour Necrosis Factor alpha

A novel viral infectious disease caused by severe acute respiratory syndrome corona virus 2 (SARS-CoV-2) was detected in Wuhan, China, in December 2019 [1]. Although initially it was contained in China, since early February 2020, the disease started to spread rapidly leading to an unprecedented pandemic of the $21^{\text {st }}$ century. As of February 5, 2021, SARS-CoV-2 has infected hundred and four million people around the world and taken away more than two million lives world-wide (https://www.medpagetoday.com/infectiousdisease/ publichealth/84698). Moreover, mutation of SARS-CoV-2 resulted in generation of new variant of coronavirus strains which are rapidly replacing other versions of the virus and establishing as the major circulating strain [2]. Entire world is working for an effective vaccine and very recently vaccine application initiated in some part of the world (https://www.who.int/emergencies/diseases/novel-coronavirus-2019/ covid-19-vaccines). Although we hope that the vaccination will be effective in preventing the spread of infection, we yet don't know about the actual effectiveness of a vaccine in controlling the pandemic and also not sure about long term protection after vaccination. Continuous mutation of SARS-CoV-2 may results in vaccine failure in near future. Over the past few weeks, COVID-19 infection has decreased in many part of the world, but in a lot of other parts, especially in the Western countries COVID-19 infection is slowly becoming a nightmare as it is increasing abruptly with lot of panic. Overall, this ongoing pandemic has put the scientific world in a puzzle. As there is no SARS-CoV-2 specific antiviral drug, it is urgently needed to find out solution which can reduce the morbidity and mortality. This can be accomplished by repurposing the therapeutics already present rather than going for the new drug development which is time consuming. Presently a lot of drugs and vaccines are under trial but their effect to control the outbreak is still uncertain.

So far critically ill patients of COVID-19 have shown acute lung injury and pneumonia which is the major cause of death among the COVID-19 positive patient [3]. The case fatality rate of this disease varies widely in different countries. Due to unavailability of specific drug to manage COVID-19 infection, at present nationwide lockdown to restrict personal contact, travel restriction, patient isolation and supportive medical care for the patient is the only way out to fight against the disease. Therefore, it is justifiable to think about combatting the mechanism used by the virus in causing acute lung injury. COVID-19 includes the symptom of acute respiratory distress syndrome (ARDS) at critical stage of illness. Cytokine storm is considered as a major cause of critical illness related to COVID-19 [4]. Ion channel of corona virus present on the envelope (E) protein was found to be related with the events of cytokine storm [5]. Cytokine storm can be inhibited by Hexamethylene Amiloride (HMA), an ion channel inhibitor and anti-cholesterol drug statin. Hence, clinical trial of these drugs may be helpful for treatment of COVID-19.

Envelope protein (E) of all corona viruses possess ion channel which is a viroporin. Virally encoded membrane pore forming viroporin proteins can modulate cellular ion channels and in a previous study on corona viruses it has been found that blocking of ion channel activity of $\mathrm{E}$ protein resulted in inhibition of viral 


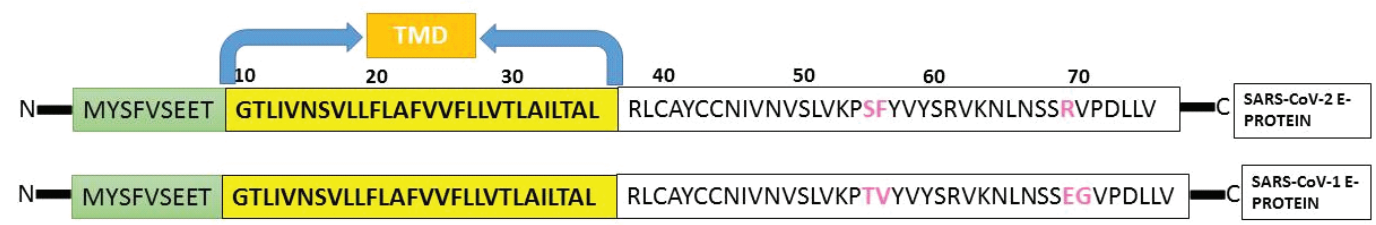

Figure 1: Amino acid sequence alignment of envelope protein of SARS-CoV-1 and SARS-CoV-2. There is no difference in the sequence of Transmembrane Domain (TMD) which forms the ion channel. Hence HMA may bind to the ion channel of SARS-CoV-2.

replication, affected virus fitness and reduced pathogenesis [5]. It was found that ion channel helps in activation of inflammasome which evokes various cytokines like interleukin $1 \beta$ (IL-1 $\beta$ ), Tumour Necrosis Factor alpha (TNF- $\alpha$ ) and interleukin 6 (IL-6) leading to ARDS and knocking down ion channel activity of E protein decreases edema, the major determinant of ARDS leading to death and also reduces the above cytokine levels [6]. Recently it was found that SARS-CoV-2 encoded protein $\mathrm{E}$, open reading frame $3 \mathrm{a}$ (ORF3a) and open reading frame $8 \mathrm{a}(\mathrm{ORF} 8 \mathrm{a})$ has ion channel activity. These ion channel proteins or viroporins activates the innate immune signaling receptor NLRP3 (NOD-, LRR-, and pyrin domain-containing 3) inflammasome via mechanisms such as lysosomal disruption and ion-redistribution in the intracellular environment which leads to the production of inflammatory cytokines such as IL- $1 \beta$, IL- 6 and TNF- $\alpha$, causing tissue inflammation during respiratory illness in SARS-CoV-2 infection $[7,8]$.

Hexamethylene amiloride, which is an inhibitor of HIV-1 Vpu virus ion channel was found to block ion channel activity of the E protein of SARS corona virus and inhibited the replication of the virus [6,9]. M2 ion channel protein of influenza A virus, a member of viroporin class, binds to the drug amantadine with high affinity. Amantadine has long been used for treatment of influenza A virus [10]. Therefore, by analogy with the use of ion channel inhibitors amantadine and rimantadine for treatment of influenza infection, HMA can be beneficial to reduce the pathogenesis of SARS-CoV-2 and associated COVID-19. Coronavirus inhibiting capacity of HMA has already been reported [6]. It has been found that HMA interacts with the transmembrane Domain (TMD) of different coronaviruses like human corona virus 229E (HCoV-229E, a group 1 coronavirus) and mouse hepatitis virus (MHV, a group 2 coronavirus). At the Nterminal end HMA binds to the transmembrane domain of $\mathrm{E}$ protein in the vicinity of N15 (Asparagine) and at the C-terminal end in the vicinity of T35 (Threonine) and R38 (Arginine). These residues are conserved in the currently circulating SARS-CoV-2 and it is expected that HMA will also interacts with E protein of SARS-CoV-2. By its property to block ion channels HMA may potentially block the ion channel to inhibit SARS-CoV-2 replication (Figure 1).

It was found that decreasing surface cholesterol of plasma membrane as well as virus surface leads to reduced binding capacity of the virus to the cell. Moreover, lipid raft is very important component of many viruses for their entry, budding and assembly including corona viruses [11]. Cholesterol lowering drugs statin may be useful in inhibiting SARS-CoV-2 by lowering cholesterol level and disrupting lipid rafts. Besides, statins have anti-inflammatory and immunomodulatory roles. As data suggest it decreases various cytokine level leading to decrease lung injury and ARDS [12]. Studies have found that prolong use of statins are also effective in ameliorating COPD [13]. Experimental data proves that statin can improve acute lung injury caused by Influenza, Pneumonia and sepsis [14]. Recently a hospital based surveillance study has shown that use of statin is associated with lower disease severity in COVID-19 infection [15]. By virtue of its cholesterol lowering activity, statin therapy was found to help in reduction of various cardiovascular disease outcomes and possible mortality in patients having influenza infection or pneumonia. COVID-19 associated deaths were found higher in patients with cardiovascular disease (10.5\%) when compared with the average population [16]. Since there is no harm associated with statin therapy, viral respiratory illnesses including COVID-19 patients could experience a beneficial effect from statin therapy.

At present, when there is no specific therapy to manage moribund illness associated with COVID-19, ion channel inhibitors and statin may be experimentally used to perceive efficacy to improve COVID condition. Therefore, there is a need for exploratory trials of these drugs and also designing of new drugs against the ion channel to combat the virus.

\section{References}

1. Biswas A, Bhattacharjee $U$, Chakrabarti AK, Tewari DN, Banu H, et al. (2020) Emergence of Novel Coronavirus and COVID-19: Whether to stay or die out? Crit Rev Microbiol 46: 182-193.

2. Tang JW, Tambyah PA, Hui DS (2020) Emergence of a new SARSCoV-2 variant in the UK. J Infect.

3. Wang D, Hu B, Hu C, Zhu F, Liu X, et al. (2020) Clinical Characteristics of 138 Hospitalized Patients with 2019 Novel Coronavirus-Infected Pneumonia in Wuhan, China. JAMA 323: 1061-1069.

4. Huang C, Wang Y, Li X, Ren L, Zhao J, et al. (2020) Clinical features of patients infected with 2019 novel coronavirus in Wuhan, China. Lancet 395: 497-506.

5. Nieto-Torres JL, DeDiego ML, Verdiá-Báguena C, Jimenez-Guardeño JM, Regla-Nava JA, et al. (2014) Severe Acute Respiratory Syndrome Coronavirus Envelope Protein Ion Channel Activity Promotes Virus Fitness and Pathogenesis. PLoS Pathog 10: e1004077.

6. Wilson L, Gage P, Ewart G (2006) Hexamethylene amiloride blocks E protein ion channels and inhibits coronavirus replication. Virology 353: 294-306.

7. Rodrigues TS, de Sá KSG, Ishimoto AY, Becerra A, Oliveira S, et al. (2021) Inflammasomes are activated in response to SARS-CoV-2 infection and are associated with COVID-19 severity in patients. J Exp Med 218: e20201707.

8. Saeedi-Boroujeni A, Mahmoudian-Sani MR, Bahadoram M, Alghasi A (2021) COVID-19: A Case for Inhibiting NLRP3 Inflammasome, Suppression of Inflammation with Curcumin? Basic Clin Pharmacol Toxicol 128: 37-45.

9. Pervushin K, Tan E, Parthasarathy K, Lin X, Jiang FL, et al. (2009) Structure and inhibition of the SARS coronavirus envelope protein ion channel. PLoS Pathog 5: e1000511. 
10. Fleming DM (2001) Managing influenza: Amantadine, rimantadine and beyond. Int J Clin Pract 1: 189-195.

11. Glende J, Schwegmann-Wessels C, Al-Falah M, Pfefferle S, Qu X, et al. (2008) Importance of cholesterol-rich membrane microdomains in the interaction of the $S$ protein of SARS-coronavirus with the cellular receptor angiotensin-converting enzyme 2 . Virology 381 : 215-221.

12. Jain MK, Ridker PM (2005) Anti-inflammatory effects of statins: Clinical evidence and basic mechanisms. Nat Rev Drug Discov 4: 977-987.

13. Lu Y, Chang R, Yao J, Xu X, Teng Y, et al. (2019) Effectiveness of longterm using statins in COPD-A network meta-analysis. Respir Res 20 : 17.
14. Fedson DS (2016) Treating the host response to emerging virus diseases: Lessons learned from sepsis, pneumonia, influenza and Ebola. Ann Transl Med 4: 421.

15. Tan WYT, Young BE, Lye DC, Chew DEK, Dalan R (2020) Statin use is associated with lower disease severity in COVID-19 infection. Sci Rep 10: 17458.

16. Dan S, Pant M, Upadhyay SK (2020) The Case Fatality Rate in COVID-19 Patients with Cardiovascular Disease: Global Health Challenge and Paradigm in the Current Pandemic. Curr Pharmacol Rep 15: 1-10. 